\title{
PLACEMENT OF A COMPOUND (N.P.K.) FER'TILIZER COMPARED WITH STRAIGHT FERTILIZERS')
}

\author{
·J. PRUMMEL
}

Institute for Soil Fertility, Groningen, Netherlands

\section{SUMMARY}

The effect of a compound fertilizer $12+10+18$ (completely water soluble) on oats and potatoes on poor soils was compared with straight fertilizers (ammonium nitrate-limestone or ammonium sulphate, double superphosphate and potassium sulphate) in two successive years, both applied in bands and by broadcasting.

The best results were obtained with placement of the compound fertilizer, providing yields higher than with straight fertilizers separately applied in bands. The beneficial effect of placement with compound fertilizer is due both to the effect of a localized application of the phosphatic constituent in the fertilizer and to the presence of nitrogen, phosphate and potash on the same place. Slightly better results were also obtained by broadcasting with compound fertilizer as compared with straight fertilizers, which may be attributed to the same factor.

We are indebted to Messrs. Albatros Superphosphate Works, Utrecht, for supplying the compound fertilizers.

\section{INTRODUCTION}

Saving of fertilizers and higher yields can generally be obtained by applying fertilizers in bands close to the plant rows. From the early stages of growth plants hereby have ample nutrients at their disposal owing to a more vigorous root development in the bands and an increasing uptake per unit of root surface. Furthermore, placement of fertilizer reduces fixation of phosphate and potash to a minimum as a result of a limited contact with the soil.

Our investigations on the present subject have so far been directed to establish the effect of the placement of straight fertilizers. With phosphate fertilizers this procedure had the greatest effect, especially on pulse crops and on maize. Cereals were more responsive than potatoes and beets. Better yields were also obtained with nitrogen and with potash fertilizers in bands $(10,11$. 12).

Compound fertilizers are technically more attractive than straight fertilizers especially when placed in bands owing to the mechanical application of two or more nutrients at once in combination with sowing or planting. Moreover, a mixture of straight fertilizers can become demixed in the distributor during the application because of the different size of the particles.

Besides these advantages of placement of compound fertilizers an other problem connected with this procedure must be considered. Pot experiments of Duncan and Ohlrogge $(1,2)$ with radio-active phosphate showed that the percentage of the total plant phosphorus derived from the fertilizer was increased by adding nitrogen and phosphate to only part of the root system rather than when the fertilizers were added to all roots. The application of nitrogen with phosphate in the same band increased the root development in the band and therefore also the phosphate uptake above that, when the two fertilizers were banded apart on opposite sides of the plant $(3,4,5,6,7)$.

1) Received for publication December 24, 1959. 
Olson, Dreier, Lowrey and Flowerday (8) found in pot experiments that mixing nitrogen in ammonium form with phosphate fertilizers gave better results in the case of banding than in that of broadcasting. RoBERTSON, SMrth, OrLROGGE and KNICH (13) experimented with ammonium sulphate, muriate of potash and superphosphate separately and mixed. Mixing of potash fertilizer with superphosphate in one band had a smaller effect than the addition of nitrogen fertilizer. The same results were obtained by Olson, Dreier, Lowrey and Flowerday (9).

When the usual straight fertilizers are applied, it may happen that all essential nutrients are not present on the same place. This will not be the case with compound fertilizers. A beneficial effect of these fertilizers applied in bands may therefore be expected.

\section{Methods}

We wanted to study the effect of placement of the combination of nitrogen, phosphate and potash in one compound fertilizer in comparison with straight fertilizers separately applied in bands under field conditions on oats and potatoes. For this purpose four field trials were carried out in two successive years. Newly reclaimed heath soils with a low nutrient content were selected in order to observe the phenomenon as clearly as possible. Two rates of the compound fertilizer (12 per cent. $\mathrm{N}, 10$ per cent. $\mathrm{P}_{2} \mathrm{O}_{5}$ (completely soluble in water), 18 per cent. $\mathrm{K}_{2} \mathrm{O}$ ) were applied (for oats 600 and $1000 \mathrm{~kg} / \mathrm{ha}$, for potatoes 900 and $1600 \mathrm{~kg} / \mathrm{ha}$ ) and compared with corresponding quantities of nutrients as straight fertilizers.

In the first year (1957) nitrogen was present completely in ammonium form, so that severe magnesium deficiency occurred. Therefore, in the second year (1958) a compound fertilizer was used with nitrogen half in ammonium and half in nitrate form. In 1957 and 1958 the straight nitrogen fertilizers were ammonium sulphate and ammonium nitrate-limestone, respectively. The other straight fertilizers used were double superphosphate $\left(44\right.$ per cent. $\mathrm{P}_{2} \mathrm{O}_{5}$, nearly all water soluble) and potassium sulphate.

The treatments were: 1. compound fertilizer broadcast, 2. compound fertilizer placed, 3. straight fertilizers broadcast, 4. ammonium sulphate or ammonium nitrate-limestone placed, other straight fertilizers broadcast, 5. superphosphate placed, other straight fertilizers broadcast, 6. potassium sulphate placed, other straight fertilizers broadcast. Eech treatment appears in fourfold replication.

The placed fertilizer was applied by a special machine, designed for experimental work (10) (for oats a single band, $3 \mathrm{~cm}$ to the side and $3 \mathrm{~cm}$ below the level of the seed, for potatoes two bands $7 \mathrm{~cm}$ on both sides and about as deep as the seed potatoes). Oats (variety Marne) were sown simultaneously with the application of the fertilizer (row distance $25 \mathrm{~cm}$ ); potatoes (variety Libertas) were afterwards handplanted (spacing $50 \times 50 \mathrm{~cm}$ ). In 1958 the potatoes were earthed up when the crop began to fill the rows (in the beginning of July). The broadcast fertilizers were applied to the seerbed and harrowed in shallowly. 


\section{Results}

\section{Development of the crop}

On both yars oats responded very clearly to double superphosphate in bands (fig. 1). Placement of ammonium nitrate-limestone and of potassium sulphate had in 1958 no benefical effect (both fertilizers applied by placement gave even at low dressing rates somewhat poorer growth than when applied by broadcasting). In 1957 placement of ammonium sulphate and of potassium sulphate were both harmful as a result of magnesium deficiency.

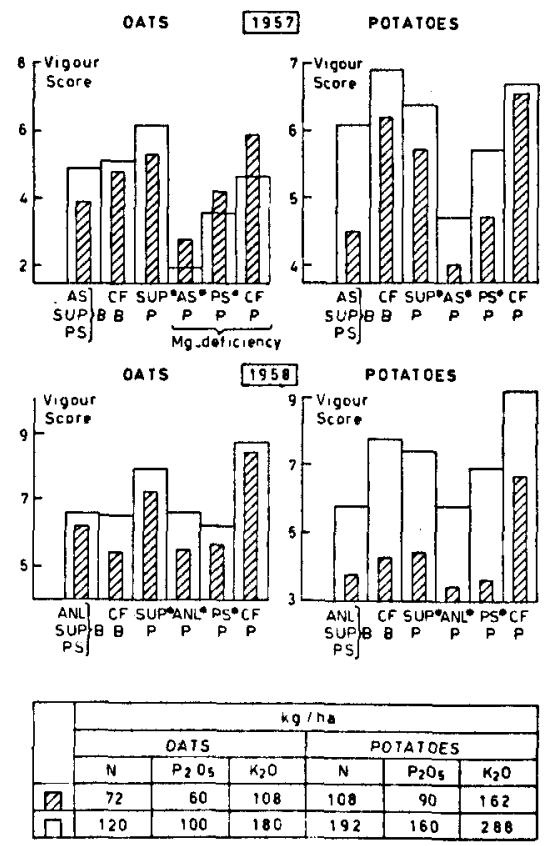

Fig 1 Influence OF FERTILIzation ON THE GROWTH OF OATS AND POTATOES IN TWO YeARS. AS $=$ ammonium sulphate, SUP $=$ double superphosphate, $\mathrm{PS}=$ potassium sulphate, $C F=$ compound fertilizer $12+10+18$, ANL $=$ ammonium nitratelimestone, $\mathbf{B}=$ broadcast, $\mathrm{P}=$ placed.

*) Other straight fertilizers broadcast.

Nevertheless, in 1957, placement of compound fertilizer was at a low rate and in 1958 at both rates more effective than with double superphosphate in bands. This effect was very spectaculair, especially in 1958 and perceptible already before tillering. These results indicate a beneficial effect of the combination of the separate nutrients in the compound fertilizer, especially for placement.

With potatoes placement of the compound fertilizer was also significantly superior to broadcast application and to straight fertilizers separately applied in bands (fig. 1). Especially in 1958 this effect was pronounced; in this year the difference in favour of placement was observed already at an early stage of growth (in late June, three weeks after emergence). Placement of compound fertilizer prolonged the period of growth.

In the case of broadcast drsesing the compound fertilizer was also bitter than straight fertilizers. 


\section{Yield}

In 1957 the yield of oats was low as a result of magnesium deficiency. Placement of the compound fertilizer produced in both years higher yields than of double superphosphate; placement of nitrogen and potash fertilizers did not show any effect and sometimes had even lower results than broadcasting

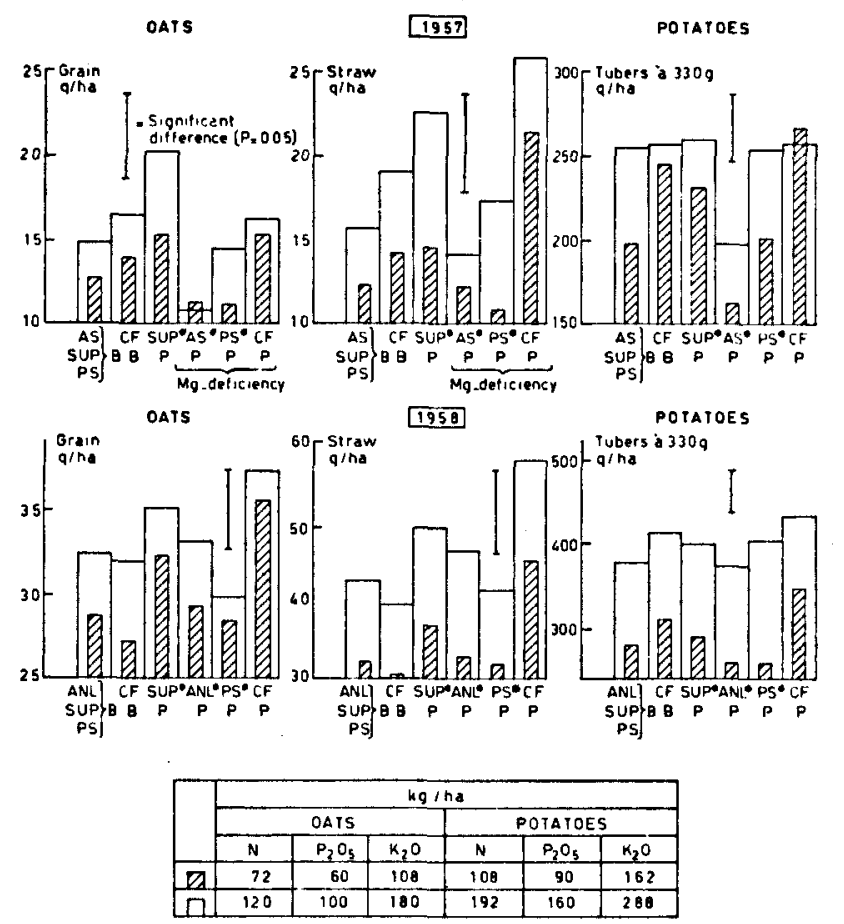

Fig. 2 SAME AS FIG. 1 FOR The Yield.

(fig. 2) In 1958 the compound fertilizer produced at a low rate in bands even a higher yield than the high rate broadcasting. The differences between the compound fertilizer placed and straight fertilizers broadcast or the compound fertilizer broadcast are significant $(P=0.05)$ for the yield of straw in 1957 and for the yield of grain and straw both in 1958.

The compound fertilizer broadcast produced higher yields of potatoes than straight fertilizers broadcast (fig. 2 for the yield of tubers, expressed recalculating on an underwater weight of $\left.330 \mathrm{~g}{ }^{1}\right)$ ). Placement with straight fertilizers separately showed only in 1957 with a low rate of double superphosphate a higher yield than broadcasting; ammonium sulphate in bands decreased the yield. Placement with the compound fertilizer produced especially at a low rate a higher yield than straight fertilizers broadcast or separately applied in bands. The differences between the compound fertilizer in bands and straight fertilizers broadcast are significant $(P=0.05)$.

On these soils, deficient in phosphate, treatment with phosphate markedly increased the underwater weight (increase from 374 to $429 \mathrm{~g}$ in 1957 and from

1) The underwater weight is determined by weighing $5 \mathrm{~kg}$ tubers under water. It is an index of the specific weight. 
411 to 460 in 1958). A high dressing with potash had a harmful influence hereupon. The highest underwater weight was obtained with compound fertilizer in bands (457 $\mathrm{g}$ in 1957, $477 \mathrm{~g}$ in 1958).

\section{Chemical composttion of the crop}

In 1957 nitrogen fertilizer in bands showed a higher phosphate content of tops and grain of oats as compared wtih broadcasting (table 1). Potash fer-

Table 1 Influence of fertilization on the nitrogen and phosphate contents of oats (tops and grain) and of potatoes (tops and tubers) in 1957.

\begin{tabular}{|c|c|c|c|c|c|c|c|c|c|}
\hline \multirow{3}{*}{\multicolumn{2}{|c|}{$\begin{array}{c}\text { Fertilizer and method of } \\
\text { application }\end{array}$}} & \multicolumn{4}{|c|}{ Oats } & \multicolumn{4}{|c|}{ Potatoes } \\
\hline & & \multicolumn{2}{|c|}{ Tops } & \multicolumn{2}{|c|}{ Grain } & \multicolumn{2}{|c|}{ Tops } & \multicolumn{2}{|c|}{ Tubers } \\
\hline & & I 1) & II 2) & I 1) & II 2) & I 3) & II 4 ) & I 3) & II $\left.^{4}\right)$ \\
\hline & $\% \mathrm{~N}$ & & & & & & & & \\
\hline AS, SUP, PS & & 2.21 & 2.56 & 2.38 & 2.56 & 4.62 & 5.12 & 1.37 & 1.48 \\
\hline & & 1.98 & 2.59 & 2.38 & 2.86 & 4.91 & 5.27 & 1.36 & 1.45 \\
\hline SUP & $\left.\mathrm{P}^{5}\right), \ldots \ldots \ldots \ldots$ & 1.98 & 2.52 & 2.28 & 2.69 & 4.66 & 5.02 & 1.23 & 1.48 \\
\hline AS & P s) & 2.20 & 2.77 & 2.52 & 2.71 & 4.75 & 5.26 & 1.29 & 1.44 \\
\hline PS & P 5) & 2.03 & 2.66 & 2.48 & 2.75 & 4.95 & 5.09 & 1.27 & 1.48 \\
\hline $\mathrm{CF}$ & $\mathrm{P} \ldots \ldots \ldots \ldots$ & 2.35 & 2.93 & 2.40 & 2.82 & 5.64 & 5.84 & 1.39 & 1.52 \\
\hline & $\% \mathrm{P}_{2} \mathrm{O}_{3}$ & & & & & & & & \\
\hline AS, SUP, PS & B $\ldots$ & 0.37 & 0.38 & 0.44 & 0.53 & 0.61 & 0.71 & 0.24 & 0.29 \\
\hline & & 0.37 & 0.49 & 0.46 & 0.58 & 0.65 & 0.80 & 0.26 & 0.35 \\
\hline SUP & P s) $\ldots$ & 0.38 & 0.47 & 0.55 & 0.74 & 0.63 & 0.72 & 0.22 & 0.27 \\
\hline AS & P s) $\ldots \ldots$ & 0.36 & 0.44 & 0.47 & 0.63 & 0.60 & 0.70 & 0.21 & 0.27 \\
\hline PS & Ps) $\ldots \ldots \ldots \ldots$ & 0.32 & 0.40 & 0.43 & 0.56 & 0.68 & 0.68 & 0.22 & 0.29 \\
\hline $\mathrm{CF}$ & $\mathrm{P} \ldots \ldots \ldots \ldots$ & 0.49 & 0.65 & 0.57 & 0.83 & 0.95 & 1.04 & 0.32 & 0.41 \\
\hline
\end{tabular}

\footnotetext{
1) $72 \mathrm{~kg} / \mathrm{ha} \mathrm{N}, 60 \mathrm{~kg} / \mathrm{ha} \mathrm{P}_{2} \mathrm{O}_{5}, 108 \mathrm{~kg} / \mathrm{ha} \mathrm{K}_{2} \mathrm{U}$

2) $120 \mathrm{~kg} / \mathrm{ha} \mathrm{N}, 100 \mathrm{~kg} / \mathrm{ha} \mathrm{P}_{2} \mathrm{O}_{5}, 180 \mathrm{~kg} / \mathrm{ha} \mathrm{K}_{2} \mathrm{O}$

3) $108 \mathrm{~kg} / \mathrm{ha} \mathrm{N}, 90 \mathrm{~kg} / \mathrm{ha} \mathrm{P}_{2} \mathrm{O}_{5}, 162 \mathrm{~kg} / \mathrm{ha} \mathrm{K}_{2} \mathrm{O}$

4) $192 \mathrm{~kg} / \mathrm{ha} \mathrm{N}, 160 \mathrm{~kg} / \mathrm{ha} \mathrm{P}_{2} \mathrm{O}_{5}, 288 \mathrm{~kg} / \mathrm{ha} \mathrm{K}_{2} \mathrm{O}$

$\mathrm{AS}=$ ammonium sulphate, $\mathrm{SUP}=$ double superphosphate, $\mathrm{PS}=$ potassium sulphate, $\mathrm{CF}=$ compound fertilizer $12+10+18, \mathrm{~B}=$ broadcast, $\mathrm{P}=$ placed.

5) Other straight fertilizers broadcast.
}

tilizer in bands showed a higher nitrogen content than broadcasting. For oats and potatoes the highest nitrogen and especially phosphate contents were mostly obtained with the compound fertilizer in bands. The same occurred in the case of potash content of oats, although less pronounced (results not included in the table).

In 1958 the chemical composition of the crop showed no higher nutrient contents with the compound fertilizer, although in this year the crop responded better in growth and in yield to placement than in 1957. In 1958 the contents did not vary much, with some exceptions. Straight fertilizers broadcast sometimes showed the highest nitrogen and potash contents and the compound fertilizer in bands the lowest. This may be partly attributed to the different forms of the nitrogen fertilizer. In 1957 the nitrogen fertilizer was ammonium and in 1958 half ammonium half nitrate. The literature contains indications that the beneficial effect of a combined nitrogen-phosphate dressing on the uptake of phosphate is less with nitrate than with ammonium $(3,7)$. 


\section{Discussion}

The experiments show that placement with a compound fertilizer gives better results than broadcasting. This must be partly attributed to the effect of a localized application in bands of the phosphatic constituent in the fertilizer. However, the effect is greater than can be expected because of the effect of the straight fertilizers separately placed. Ammonium nitrate-limestone or ammonium sulphate and potassium sulphate localized in bands are mostly not better or sometimes even less satisfactory than broadcast. The slightly better results with the compound fertilizer broadcasting as compared with straight fertilizers broadcasting likewise indicates a beneficial effect of the combination of nitrogen, phosphate and potash in the same spot. In agreement with other investigations the compound fertilizer in bands showed in one of the experiment years higher nutrient contents than with straight fertilizers.

For this reason placement with compound fertilizers offers a possibility to achieve a better effect than is attainable with straight fertilizers. These trials on very poor soils have not yet furnished the proof that the effect will also arise under more normal conditions on more fertile soils. In further research attention will be paid to soils with a higher content of nutrients.

\section{REFERENCES}

1 Duncan, W. G. and A. J. Ohlrogge : Principles of nutrient uptake from fertilizer bands : II. Root development in the band. Agronomy Journal 50, 10 (1958) 605-608.

2 - -, - - : Principles of nutrent uptake from fertilizer bands : III. Band volume, concentration and nutrient composition. Agronomy Journal 51, 2 (1959) 103-106.

3 Fine, L. O.: The influence of nitrogen and potassium on the availability of fertilizer phosphorus. South Dakota Exp. Sta. Bul. 453 (1955). North Central Regional Publ. 67.

4 Grunes, D. L., F. G. Viets JR. and S. H. ShrH : Proportionate uptake of soil and fertilizer phosphorus by plants as affected by nitrogen fertilization: I. Growth chamber experiment. Soil Sci. Soc. Amer. Proc. 22, 1 (1958) 43-48.

$5--$, H. R. HAISE and L. O. FInE: Proportionate uptake of soil and fertilizer phosphorus by plants as affected by nitrogen fertilization: II. Field experiments with sugar beets and potatoes. Soil Sci. Soc. Amer. Proc. 22, 1 (1958) 49-52.

6 Mrller, M. H. and A. J. Ohlrogge: Principles of nutrient uptake from fertilizer bands : I. Effect of placement of nitrogen fertilizer on the uptake of band-placed phosphorus at different soil phosphorus levels. Agronomy Journal 50, 2 (1958) 95-97.

7 Orson, R. A. and A. F. Dreier: Nitrogen, a key factor in fertilizer phosphorus efficiency. Soil Sci. Soc. Amer. Proc. 20, 4 (1956) 509-514.

$8--,--$, G. W. Lowrey and A. D. FLowerday : Availability of phosphate carriers to small grains and subsequent clover in relation to: I. Nature of soil and method of placement. Agronomy Journal 48, 3 (1956) 106-111.

$9--,--,--,--$ : Availability of phosphate carriers to small grains and subsequent clover in relation to : II. Concurrent soil admendments. Agronomy Joumal 48,3 (1956) 111-116.

10 Prummel, J. : Fertilizer placement experiments. Plant and Soil 8, 3 (1957) 231-253.

11 - - : Rijenbemesting met fosfaat bij peulvruchten en mais. Landbouwvoorlichting 15, 2 (1958) 83-91.

12 - - : Rijenbemesting met fosfaat bij stamslabonen. Technische berichten Peulvruchten Studie Combinatie 82 (1959) 1-8.

13 Robertson, W. K., P. M. Smith, A. J. Ohlnogge and D. M. Knich : Phosphorus utilization by corn as affected by placement and nitrogen and potassium fertilization. Soil Sci. 77, 3 (1954) 219-226. 